\title{
Drug utilization pattern in Schizophrenia
}

\author{
Elza Joy Munjely ${ }^{1 *}$, Bindu Latha Nair R. ${ }^{2}$, Varghese P. Punnoose ${ }^{3}$
}

${ }^{1}$ Department of Pharmacology, Government Medical College, Kottayam, Kerala, India ${ }^{2}$ Department of Pharmacology, Government Medical college, Kollam, Kerala, India ${ }^{3}$ Department of Psychiatry, Government TD Medical College, Alappuzha, Kerala, India

Received: 16 April 2019 Accepted: 30 May 2019

*Correspondence to: Dr. Elza Joy Munjely, Email:

elzajoymoonjely@gmail.com

Copyright: (C) the author(s), publisher and licensee Medip Academy. This is an openaccess article distributed under the terms of the Creative Commons Attribution NonCommercial License, which permits unrestricted noncommercial use, distribution, and reproduction in any medium, provided the original work is properly cited.

\begin{abstract}
Background: Pharmacotherapy is the mainstay of treatment in schizophrenia. The economic impact of this illness is wide ranging, long lasting and huge. The emergence of newer antipsychotics has changed the prescribing pattern. Purpose of this study is to determine the prescription pattern of antipsychotic drugs and to analyse the drug utilization in patients with schizophrenia based on WHO prescribing indicators.

Methods: A descriptive study was conducted for a period of 1-year duration at inpatient Department of Psychiatry of a Government Medical College in Kerala, India among 230 schizophrenic patients. The case sheets of patients meeting inclusion criteria were scrutinised to find out the antipsychotic prescription pattern and drug utilization was analysed using WHO prescribing indicators. Analysis was done using descriptive statistics.

Results: Newer antipsychotics (55.2\%) were prescribed slightly more in preference to older antipsychotic $(44.8 \%)$ drugs. Out of the newer drugs prescribed olanzapine $(20.9 \%)$ was prescribed the most followed by risperidone (18\%). Haloperidol (22.9\%) was the most frequently prescribed older antipsychotic. Majority $(71.3 \%)$ of the patients were given more than one antipsychotics during the hospital stay. Trihexyphenidyl (27.9\%) was the most frequently co-prescribed drug with antipsychotics. Average number of drugs per encounter was $4.19,73.4 \%$ of the drugs were prescribed in their generic name, $50.4 \%$ of the encounters were with an injection prescribed. $44.4 \%$ of the drugs were prescribed from the EDL (WHO-19th edition). Average drug cost per encounter was Rs.45.43. Percentage of drug cost spent on injections was $8.44 \%$. Conclusions: Newer antipsychotics were more prescribed for schizophrenia of which olanzapine was the commonest. Newer antipsychotics are preferred because of their propensity to cause less side effects and more efficacy. Study of pattern of drug utilization is useful for measuring the economic impact of drug use among patients thereby facilitating rational prescribing.
\end{abstract}

Keywords: Antipsychotics, Drug utilization, Prescription pattern, Schizophrenia, WHO prescribing indicators

\section{INTRODUCTION}

The field of psychopharmacology is rapidly expanding. It is challenging the traditional concepts of psychiatric treatment and research and is constantly seeking new and improved drugs to treat psychiatric disorders. In this way, psychiatrists are continuously exposed to newly introduced drugs that are claimed to be safe and more efficacious. ${ }^{1}$

Antipsychotics (also known as neuroleptics) are a class of psychiatric medication primarily used to manage psychosis (including delusions, hallucinations, or disordered thought), in particular in schizophrenia and 
bipolar disorder. More than 30 different antipsychotic drugs are available for clinical use. These can be divided into two groups those drugs that were originally developed (eg:chlorpromazine, haloperidol), often referred to as firstgeneration, typical or conventional antipsychotic drugs, and most recently developed agents(eg: clozapine, risperidone), which are termed atypical antipsychotic drugs. ${ }^{2}$ The treatment of choice of schizophrenia for the past 40 years is antipsychotic monotherapy. ${ }^{3}$ In the earlier days conventional antipsychotics were used. But with the advent of the second generation antipsychotics which are more efficacious and with better tolerability, they have become the first line drugs for the treatment of schizophrenia. ${ }^{4,5}$ However the cost of second generation antipsychotics have been 10 times more than those of first generation antipsychotics. ${ }^{6}$ These cost differences is the main contributor to relatively low prescription rates of second generation antipsychotics in developing countries. ${ }^{7}$ Many other factors have also influenced the prescription patterns like clinicians/patient preferences, traditional medicines, socioeconomic factors or cultural underpinnings. ${ }^{8}$

Drug utilization study has been defined by the World Health Organization (WHO) as The marketing, distribution, prescription and uses of drugs in a society with special emphasis on the resulting medical, social and economical consequence. ${ }^{1}$ The principal aim of the drug utilization research is to facilitate the rational use of the drugs. Rational drug prescribing is the use of the least number of drugs to obtain the best possible effect in the shortest period and at a reasonable cost. ${ }^{9}$ Without the knowledge of how the drugs are being prescribed, it is difficult to suggest the measures to improve prescribing habits. This study is to analyze the drug utilization pattern in patients with schizophrenia admitted to psychiatry inpatient department of Government Medical College Kottayam, Kerala, India.

\section{METHODS}

A descriptive study was conducted in the inpatient department of Psychiatry of Government Medical College, Kottayam, Kerala, India after approval from the Institutional Ethics Committee. The study was conducted over a period of 12 months from March 2016 to February 2017. Based on the data obtained from a similar study conducted in India, sample size was calculated to be $230 .{ }^{10}$ Informed consent was obtained from the patients legally acceptable representative. The study population included patients in all the age groups and both the sexes. All patients diagnosed by psychiatrists as schizophrenia and on antipsychotics were recruited for the study till the sample size was reached. Data was collected from the patient's case sheets using a structured proforma. Demographic details of the patient and details of the all the drugs prescribed like dose, route, and frequency of administration were recorded in the proforma. The duration of hospital stay was also noted. The total drug cost during their present hospital stay was calculated by adding the cost spent on drugs each day from the day of admission to the day of discharge with the help of price list obtained from the hospital pharmacy. All data were entered in MS Excel. Descriptive analysis was done using SPSS 16 software. Qualitative variables were expressed as frequencies and percentages. Quantitative variables were expressed as mean +/- standard deviation. Data were also analysed using WHO prescribing indicators

- $\quad$ Average number of drugs per encounter

- Percentage of drugs prescribed by generic name

- Percentage of encounters with an injection prescribed

- $\quad$ Percentage of drugs prescribed from Essential Drug List (WHO-19th edition)

- Average drug cost per encounter

- Percentage of drug cost spent on injections. ${ }^{11,12}$

\section{RESULTS}

The study analysed prescription pattern of 230 schizophrenic patients who were on antipsychotics. Among these $150(65 \%)$ patients were males and $80(35 \%)$ were females. Mean age was 34.8 ( $\mathrm{SD}=12.19)$ years. Youngest patient was 14 years and eldest one was 68 years. Maximum number of patients $(n=76,33 \%)$ were in the age group 20-30 years. Table1 shows the age-gender distribution.

Table 1: Age-gender distribution.

\begin{tabular}{|llll|}
\hline \multirow{2}{*}{ Age in years } & $\begin{array}{l}\text { Gender } \\
\text { Male }\end{array}$ & Female & Total \\
\hline$<20$ & 10 & 9 & 19 \\
\hline $20-30$ & 47 & 29 & 76 \\
\hline $31-40$ & 43 & 25 & 68 \\
\hline $41-50$ & 32 & 5 & 37 \\
\hline $51-60$ & 16 & 8 & 24 \\
\hline$>60$ & 2 & 4 & 6 \\
\hline Total & 150 & 80 & 230 \\
\hline
\end{tabular}

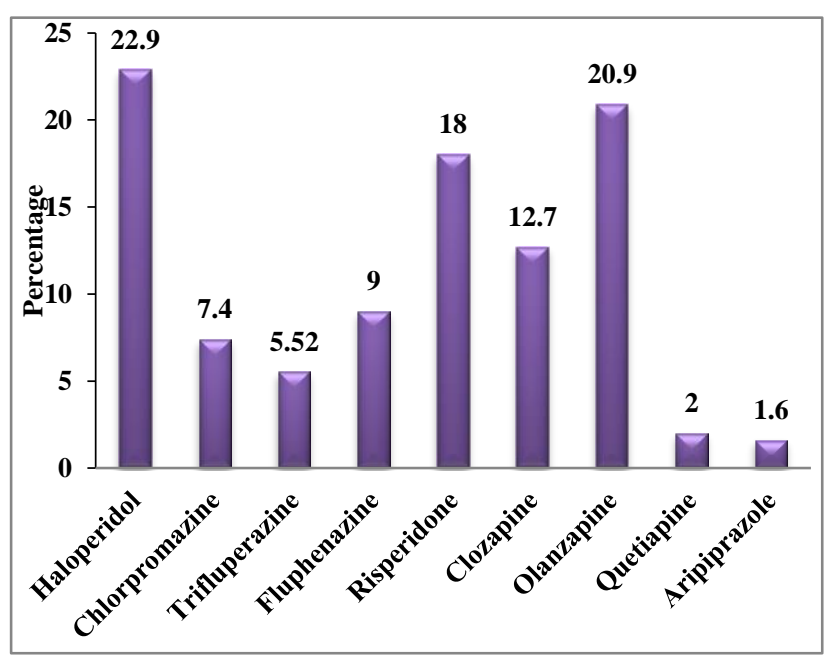

Figure 1: Pattern of antipsychotic prescription. 
Total number of drugs given for the 230 schizophrenic patients were 963, of which 489 (50.8\%) were antipsychotic drugs and 474 (49.2) were concomitant drugs. Out of 489 antipsychotic drugs, 270(55.2\%) were newer and 219 (44.8\%) were conventional antipsychotics. Among the newer drugs olanzapine $(n=102,20.9 \%)$ was the most frequently prescribed drug. Haloperidol $(n=112$, $22.9 \%$ ) was the most frequently prescribed conventional antipsychotic. The antipsychotic prescription pattern is as shown in the Figure 1.

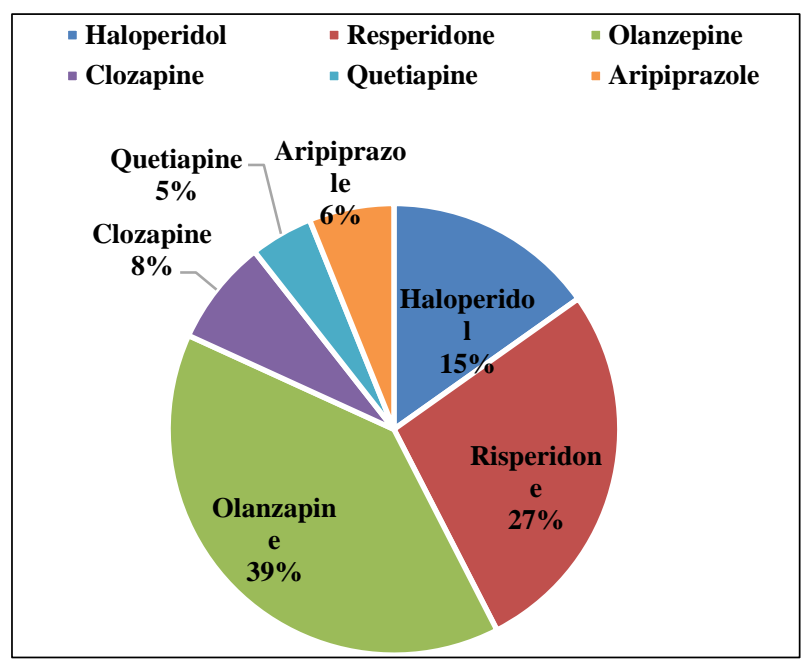

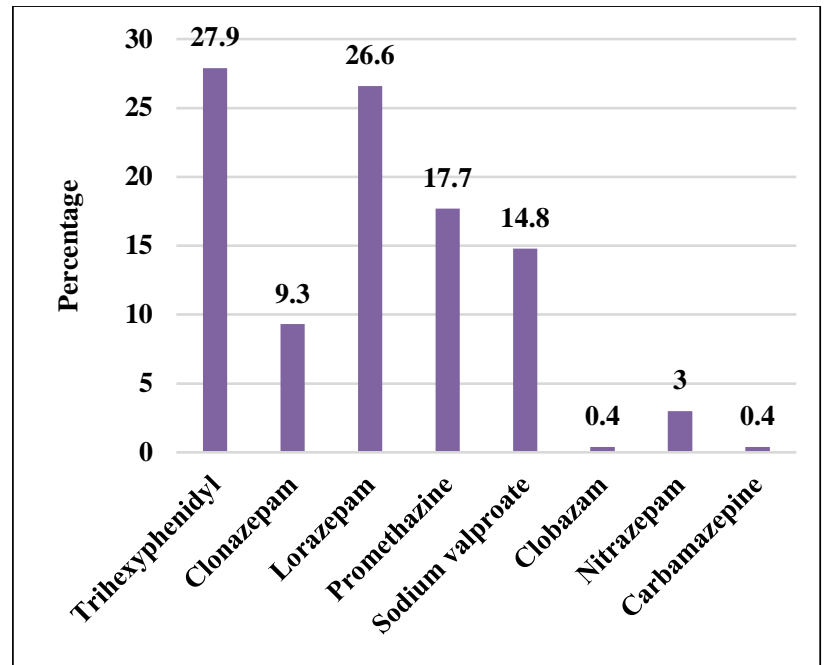

Figure 3: Pattern of prescription of concomitant drugs.

Among 230 patients, 164(71.3\%) received multiple antipsychotics while rest of the patients, 66(28.7\%) received single drug. Most frequently given monotherapy was olanzapine $(n=26,39 \%)$.

Figure 2 shows the percentage of prescriptions of various antipsychotics used as monotherapy.

Figure 2: Antipsychotics used as monotherapy.

Table 2: Analysis of drug utilization pattern using WHO prescribing indicators.

\begin{tabular}{|lll|}
\hline \multicolumn{2}{|c|}{ WHO prescribing indicators } & Results \\
\hline 1 & Average number of drugs per encounter & 4.19 \\
\hline 2 & Percentage of drugs prescribed by generic name & $73.4 \%$ \\
\hline 3 & Percentage of encounters with an injection prescribed & $50.4 \%$ \\
\hline 4 & Percentage of drugs prescribed from Essential Drug List (WHO-19 ${ }^{\text {th }}$ edition) & $44.4 \%$ \\
\hline 5 & Average drug cost per encounter & Rs.45.43 \\
\hline 6 & Percentage of drug cost spent on injections & $8.44 \%$ \\
\hline
\end{tabular}

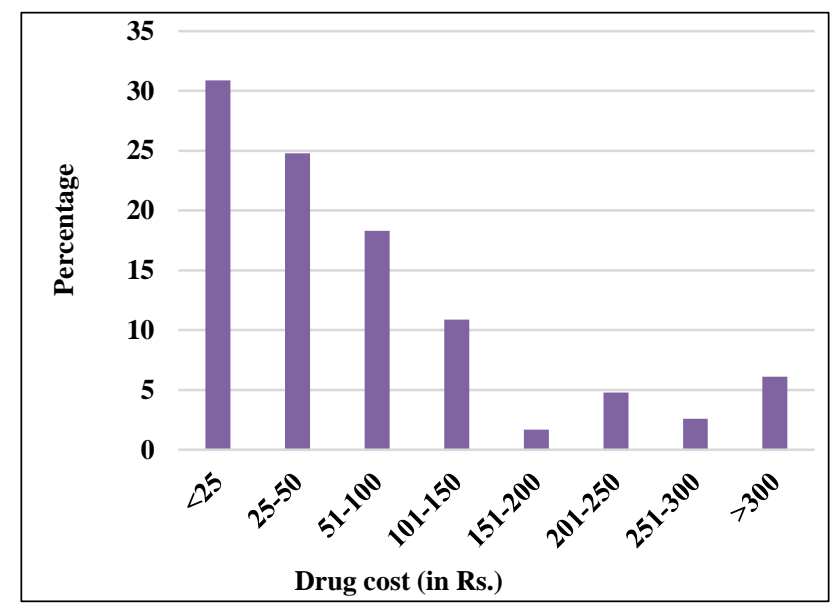

Figure 4: Drug cost during the hospital stay.
Among the patients who received multiple antipsychotics maximum number $(\mathrm{n}=92,40 \%)$ of patients were given 2 antipsychotics. 3,4 and 5 antipsychotics were prescribed for $55(24 \%), 11(5 \%)$ and $6(2 \%)$ patients respectively. 116 $(50.4 \%)$ patients received parenteral drugs. 114(49.6\%) patients received oral drugs exclusively. Most frequently prescribed parenteral preparations were of promethazine $(n=86,36.1 \%)$ and haloperidol $(n=85,35.3 \%)$ followed by fluphenazine $(n=49,20.6 \%)$, lorazepam $(n=14,5.9 \%)$ and olanzepine $(n=4,1.7 \%)$. Trihexyphenidyl $(n=132,27.9 \%)$ was the drug which was coprescribed most frequently with antipsychotics. The pattern of prescription of concomitant drugs is as shown in the Figure 3.

Majority ( $\mathrm{n}=85,37.4 \%)$ of the patients stayed 1-2 weeks in the hospital. Number of patients stayed less than a week was $40(17.4 \%)$ and more than 4 weeks was $42(18.3 \%)$. It 
was found that, for majority ( $n=71,30.9 \%)$ of the schizophrenic patients, drug cost was less than Rs.25 during the hospital stay. Figure 4 shows the drug cost during the hospital stay.

\section{DISCUSSION}

This study gives information regarding prescription pattern of antipsychotics. It also determines the pattern of utilisation of drugs based on WHO prescribing indicators. This study shows a gender preponderance of schizophrenia to male patients and age preponderance to young adults (20-30 years) which is comparable to the findings of other similar studies. ${ }^{10,13}$

Almost all of the recent prescription pattern studies of antipsychotics concluded that, atypical antipsychotics are most frequently prescribed than typical antipsychotics due to their ability to cause low incidence of extrapyramidal side effects and better control of symptoms. ${ }^{5,6,10}$ This is consistent with present study in which atypical antipsychotics were prescribed more than typical ones. In present study haloperidol $(22.9 \%)$ was the most frequently prescribed antipsychotic followed by Olanzepine (20.9\%), Resperidone (18\%) Clozapine (12.7\%), Fluphenazine (9\%), Chlorpromazine (8.2\%), Trifluperazine (7.4\%), Quetiapine (2\%) and Aripiprazole (1.6\%). In a similar Indian study conducted by Iliaz et al. in 2013-2014, most commonly prescribed antipsychotic was Resperidone $(40.8 \%)$ followed by Quetiapine $(8.62 \%)$, Olanzapine $(4.02 \%)$, Amisulpride (4.02\%), Aripiprazole (0.57\%). ${ }^{5}$

In present study majority $(71.3 \%)$ of the patients received multiple antipsychotics during their hospital stay amongst which most of the patients were treated with 2 antipsychotics and rest with 3,4 and 5 antipsychotics in decreasing order of frequency. These patients either received them concomitantly or switched from one to another depending upon the clinical response. The dose of the antipsychotics were cross titrated gradually when they were to be given concomitantly or if there was switching over from one antipsychotic to another. Rest of the patients $(28.7 \%)$ were received single drug. Most frequently given monotherapy was olanzepine $(39.4 \%)$ followed by resperidone $(27.3 \%)$, haloperidol $(15.2 \%)$, clozapine (7.6\%), aripiprazole (6.1\%), quetiapine (4.5\%). Concomitant drug like trihexyphenidyl served the purpose of reducing the extrapyramidal side effects of antipsychotics by its anticholinergic antiparkinsonian action. Rest of the concomitant drugs were to impart a sedative effect on agitated patients and to stabilize their mood. Findings from a similar study done in Korea by Kim et al. shows that unlike in our study, majority (79.7\%) of patients were treated with a single antipsychotic drug, while $19.2 \%$ were prescribed two antipsychotic drugs and $1.2 \%$ were prescribed three antipsychotic drugs. Of the total patients receiving monotherapy only $6.9 \%$ were prescribed a typical antipsychotic, while $93.1 \%$ were prescribed an atypical antipsychotic. The most frequently prescribed antipsychotic medications in the monotherapy group were risperidone $47.2 \%$, olanzepine $14.5 \%$, aripiprazole $11.4 \% .{ }^{14}$

Average number of drugs per prescription is an important index of prescription audit. ${ }^{15}$ It helps us to measure the degree of polypharmacy. ${ }^{16,17}$ In the present study, the average number of drugs per prescription is four. Large proportion $(73.4 \%)$ of the drugs were prescribed in their generic name. Percentage of encounters with an injection prescribed, helps to measure the overall level of use of two important, but commonly overused and costly forms of drug therapy. ${ }^{18,19}$ Almost half of the evaluated schizophrenic patients received injections. Of the injections, most commonly prescribed were that of promethazine and haloperidol. Utilization of drugs from Essential Drug List (WHO-19th edition) was 44.4\%. In a pharmacoepidemiological study of antipsychotics conducted by Lahon $\mathrm{K}$ et al. derived conclusions that average number of drugs per prescription was 2.19, percentage of antipsychotic drugs prescribed by generic name was $63.64 \%$, percentage of encounters with an injection prescribed was $3.03 \%$, percentage of drugs prescribed from WHO essential medicines list was $3.03 \% .{ }^{20}$ In order to rationalise the drug use, it is important to determine the cost analysis. ${ }^{21,22}$ Average drug cost per encounter was determined by dividing total costs of all drugs prescribed by the number of encounters surveyed which was Rs. 45.43. Hence in a government setup treatment of schizophrenia is not much a financial burden for the patient's family. $8.44 \%$ of the total drug cost was spent on injections. In a drug utilization study conducted by Thakkar KB et al. among outpatients, the average cost per prescription was Rs. 178 or 3.2 USD. ${ }^{23}$

\section{CONCLUSION}

Newer antipsychotics were slightly more preferred than the conventional antipsychotics. Olanzapine and haloperidol were the most frequently prescribed newer and conventional antipsychotic drugs respectively. Polytherapy was more common when compared to monotherapy in treatment of Schizophrenia. Average drug cost per encounter was Rs.45.43 which was affordable in a government setup. Limitations of this study were patients' follow up was not done. Patient compliance, adverse drug reactions and adherence to standard treatment guidelines could not be assessed. Drug utilization was not evaluated by means of drug utilization matrices like Defined Daily Dose (DDD) or Prescribed Daily Dose (PDD). Only inpatients were included in this study. Limited availability of drugs in hospital pharmacy, limitations in man-power and infrastructure leading to higher use of parenterals are also the limiting factors of this study

\section{ACKNOWLEDGEMENTS}

Authors would like to thank Dr. Dhanya SP, Associate Professor (CAP), Department of Pharmacology, Government Medical College, Kottayam Kerala, India. 
Funding: No funding sources

Conflict of interest: None declared

Ethical approval: The study was approved by the Institutional Ethics Committee (IEC No:13/2016)

\section{REFERENCES}

1. Piparva KG, Parmar DM, Singh AP, Gajera MV, Trivedi HR. Drug utilization study of psychotropic drugs in outdoor patients in a teaching hospital. Indian J Psychol Med. 2011;33(1):54-8.

2. Rang HP, Dale MM, Ritter JM, Flower RJ, Henderson G. Rang and Dale's Pharmacology.7th ed. Edinburgh: Churchill Livingstone; Chapter 45: Antipsychotic drugs; 2012:553-563.

3. Zhu B, Svanum AH, Faries DE, Correll CU, Kane JM. Cost of antipsychotic polypharmacy in the treatment of schizophrenia. BMC Psychiatry. 2008;8(1):19.

4. He X, Wu J, Jiang Y, Liu L, Ye W, Xue H, et al. Health care resource utilization and direct medical costs for patients with schizophrenia initiating treatment with atypical versus typical antipsychotics in Tianjin, China. BMC Health Serv Res. 2015;15(1):149.

5. Ilyaz M, Baig MMA, Ramakrishna, Quadir MA, Fathima M, Khan SAS. Drug utilization study of antipsychotics and its common ADR's in the psychiatry OPD of OHRC. Int J Pharm Pharm Sci. 2014;6(9). Available at: http://innovareacademics.in/journals/index.php/ijpps/ article/view/1456 [cited 2015 Sep 24]

6. Weinbrenner S, Assion HJ, Stargardt T, Busse R, Juckel G, Gericke CA. Drug prescription patterns in schizophrenia outpatients: analysis of data from a German health insurance fund. Pharmacopsychiatry. 2009;42(2):66-71.

7. Loosbrock DL, Zhao Z, Johnstone BM, Morris LS. Antipsychotic medication use patterns and associated costs of care for individuals with schizophrenia. J Ment Health Policy Econ. 2003;6(2):67-76.

8. Park SC, Lee MS, Kang SG, Lee SH. Patterns of antipsychotic prescription to patients with schizophrenia in Korea: results from the health insurance review and Assessment Service-national patient sample. J Korean Med Sci. 2014;29(5):719-28.

9. Lahonak, Shetty HM, Paramel A, Sharma G. Retrospective drug utilization study of antidepressants in the psychiatric unit of a tertiary care hospital. J Clini and Diagc Res. 2011;5(5):1069-75.

10. Devi PD, Amarjeeth R, Sushma M, Guido S. Prescription patterns of psychotropic drugs in hospitalized schizophrenic patients in a tertiary care hospital. Calicut Med J. 2007;5(4):e3.

11. How to Investigate Drug Use in Health Facilities: Selected Drug Use Indicators - EDM Research Series No. 007: Chapter 2: Core drug use indicators: Group 1: Prescribing indicators [Internet]. [cited 2017 Nov $6]$. Available
http://apps.who.int/medicinedocs/en/d/Js2289e/3.1.ht $\mathrm{ml}$.

12. WHO | WHO Model Lists of Essential Medicines [Internet]. WHO. [cited 2016 Mar 8]. Available at: http://www.who.int/medicines/publications/essential medicines/en/

13. Judy MV. Psychiatric disorder. Cultural and demographic factors of schizophrenia. Int J Psychol Rehab. 2012;10(2):89-103.

14. Kim HY, Lee HW, Jung SH, Kang MH, Bae JN, Lee JS, et al. Prescription patterns for patients with schizophrenia in Korea: a focus on antipsychotic polypharmacy. Clin Psycho pharmacol Neurosci. 2014;12(2):128-36.

15. Bergman U, Popa C, Tomson Y, Wettermark B, Einarson TR, Åberg H, et al. Drug utilization 90\%- a simple method for assessing the quality of drug prescribing. Eur J Clin Pharmacol. 1998;54(2):113-8.

16. Laporte JR, Porta M, Capella D. Drug utilization studies: a tool for determining the effectiveness of drug use. Br J Clin Pharmacol. 1983;16(3):301-4.

17. Drug Utilization Studies: Methods and Uses. Available http://apps.who.int/medicinedocs/en/d/Js21868en/. Accessed 8 November 2017.

18. Hartzema AG, Porta MS, Tilson HH, Serradell J, Bjornson DC, Hartzema AG. Drug utilization study methodologies: national and international perspectives. Drug Intell Clin Pharm. 1987;21(12):994-1001.

19. Bachhav SS, Kshirsagar NA. Systematic review of drug utilization studies and the use of the drug classification system in the WHO-SEARO Region. Indian J Med Res. 2015;142(2):120.

20. Lahon K, Paramel A, Shetty H, Sharma G. Pharmacoepidemiological study of antipsychotics in the psychiatry unit of a tertiary care hospital: a retrospective descriptive analysis. Int $\mathbf{J}$ Nutr Pharmacol Neurol Dis. 2012;2(2):135.

21. Drug prescribing pattern and cost analysis of antipsychotics at a tertiary care hospital | international journal of pharmaceutical sciences and research [Internet]. Available at: http://ijpsr.com/bftarticle/drug-prescribing-pattern-and-cost-analysis-ofantipsychotics-at-atertiary-carehospital/?view=fulltext. Accessed 6 November 2017.

22. Rode S, Salankar H, Verma P, Sinha U, Ajagallay RK. Pharmacoepidemiological survey of schizophrenia in Central India. Int J Res Med Sci. 2014;2(3):1058-62.

23. Thakkar KB, Jain MM, Billa G, Joshi A, Khobragade AA. A drug utilization study of psychotropic drugs prescribed in the psychiatry outpatient department of a tertiary care hospital. J Clin Diagn Res. 2013;7(12):2759-64.

Cite this article as: Munjely EJ, Bindu Latha Nair BLR, Punnoose VP. Drug utilization pattern in Schizophrenia. Int J Basic Clin Pharmacol 2019;8:1572-6. 